\title{
Minipuberty: Why Does it Happen?
}

\author{
Marianne Becker ${ }^{a} \quad$ Volker Hesse ${ }^{b}$ \\ aPediatric Endocrinology and Diabetology (DECCP), Centre Hospitalier de Luxembourg, Luxembourg, Luxembourg; \\ ${ }^{b}$ DEUZWEG German Center for Growth, Development and Health Promotion in Childhood and Adolescence, Berlin, \\ Germany
}

\section{Keywords}

Minipuberty · Testosterone · Estradiol · Gonadotropin ·

Hypothalamic-pituitary-gonadal axis

\begin{abstract}
Minipuberty describes the transient sex-specific activation of the hypothalamic-pituitary-gonadal (HPG) axis during the first 6 months of life in boys and during the first 2 years in girls. It leads to a rise of luteinizing hormone, follicle-stimulating hormone, estradiol, and testosterone. The existence of minipuberty has been known for $>40$ years, but we still do not fully understand why it takes place. Current thinking suggests that it is an essential imprinting period for different body functions. Firstly, minipuberty plays an important role in genital organ development; testosterone influences penile growth, the number of Sertoli cells, and spermatogenesis. Secondly, it seems to influence the infant's body composition; testosterone likely has an imprinting effect on BMI and body weight of boys and growth velocity in the first 6 months of life. Thirdly, it affects cognitive functions; testosterone has an impact on language organization in the infant brain and estradiol affects laryngeal sound production and baby babbling. There are inconsistent findings concerning the impact of minipuberty on sex-specific playing behavior. Minipuberty is an interesting field of research, and further studies in this area will teach us more about this exciting period of human development.

(c) 2020 S. Karger AG, Basel
\end{abstract}

\section{Introduction}

Puberty is the physical maturation of a child's body into an adult body which is capable of sexual reproduction. This maturation is induced by an activation of the hypothalamic-pituitary-gonadal (HPG) axis which causes a gender-specific elevation in the gonadotropic hormones (luteinizing hormone [LH] and folliclestimulating hormone [FSH]) and sex steroid hormones (testosterone in males and estradiol in females). Classical (canonical) puberty occurs in adolescence, but the HPG axis is activated prior to this, once in utero and once in the first months of life. The first 2 activations of the HPG axis neither induce physical pubertal changes (no change in Tanner stage) nor result in the capacity for reproduction. But the HPG axis activations in utero and during the first months of life do induce a gender-specific elevation in sex hormones; they could, therefore, be described as "endocrine puberties." Hence, humans experience 3 "endocrine puberties" [1] throughout life (Table 1; Fig. 1, 2). This review focuses on the second transient endocrine puberty, also called "minipuberty." We address the issue of why humans experience 3 endocrine puberties and not just 1. We examine which changes are induced by minipuberty and its functions.

\section{KARGER}

(C) 2020 S. Karger AG, Basel 


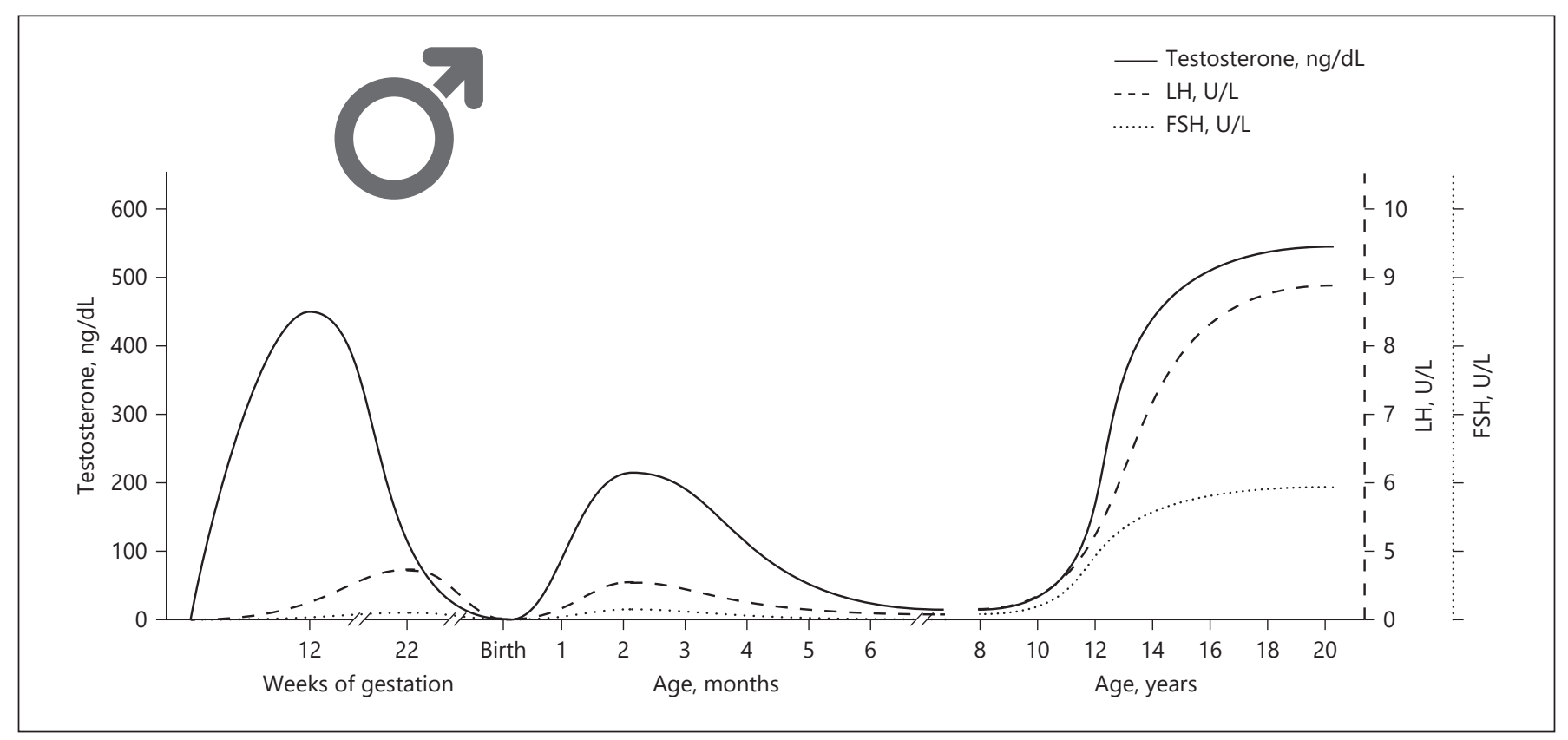

Fig. 1. Pattern of LH, FSH, and testosterone during the 3 endocrine puberties in boys.

Table 1. The 3 endocrine puberties during human development (according to Hesse [1])

\begin{tabular}{lll}
\hline & Time period & First description \\
\hline 1. Intrauterine & weeks 10-24 of gestation & $\begin{array}{l}\text { Grumbach and Kaplan [3], 1974; } \\
\text { Reyes et al. [6], 1974 }\end{array}$ \\
\hline 2. Postnatal & 1-6 months & Forest et al. [10], 1973 \\
\hline 3. Classic (canonical) puberty & $\begin{array}{l}\text { girls: onset at } 8-13 \text { years } \\
\text { boys: onset at 9-14 years } \\
\text { variable duration of 3.5-4.5 years }\end{array}$ & \\
\hline
\end{tabular}

\section{Hormonal Analysis}

Studies targeting minipuberty are based on hormone measurements in different matrices (the blood, saliva, and urine) and at different time points. Further studies are needed to evaluate the reliability of hormone-sampling methods in the saliva and urine. Recent data show that direct immunoassays overestimate testosterone concentrations, especially in female newborns, and that measurement by liquid chromatography-tandem mass spectrometry (LC-MS/MS) is more reliable [2]. Hence, sampling material and analytical method should be taken into account when evaluating studies on minipuberty. In this review, for each study, we will indicate the applied sampling method, so as to enable the reader to make the best possible assessment of the data presented.

\section{A Short Description of the First Endocrine Puberty}

The first transient pubertal period takes place in utero [3] between the 10th and 24th gestational week. Levels of LH and FSH (measured by radioimmunoassay [RIA]) peak at midgestation and progressively decline thereafter, until being completely suppressed at birth [4] by the rising concentration of placental estrogen [5]. 


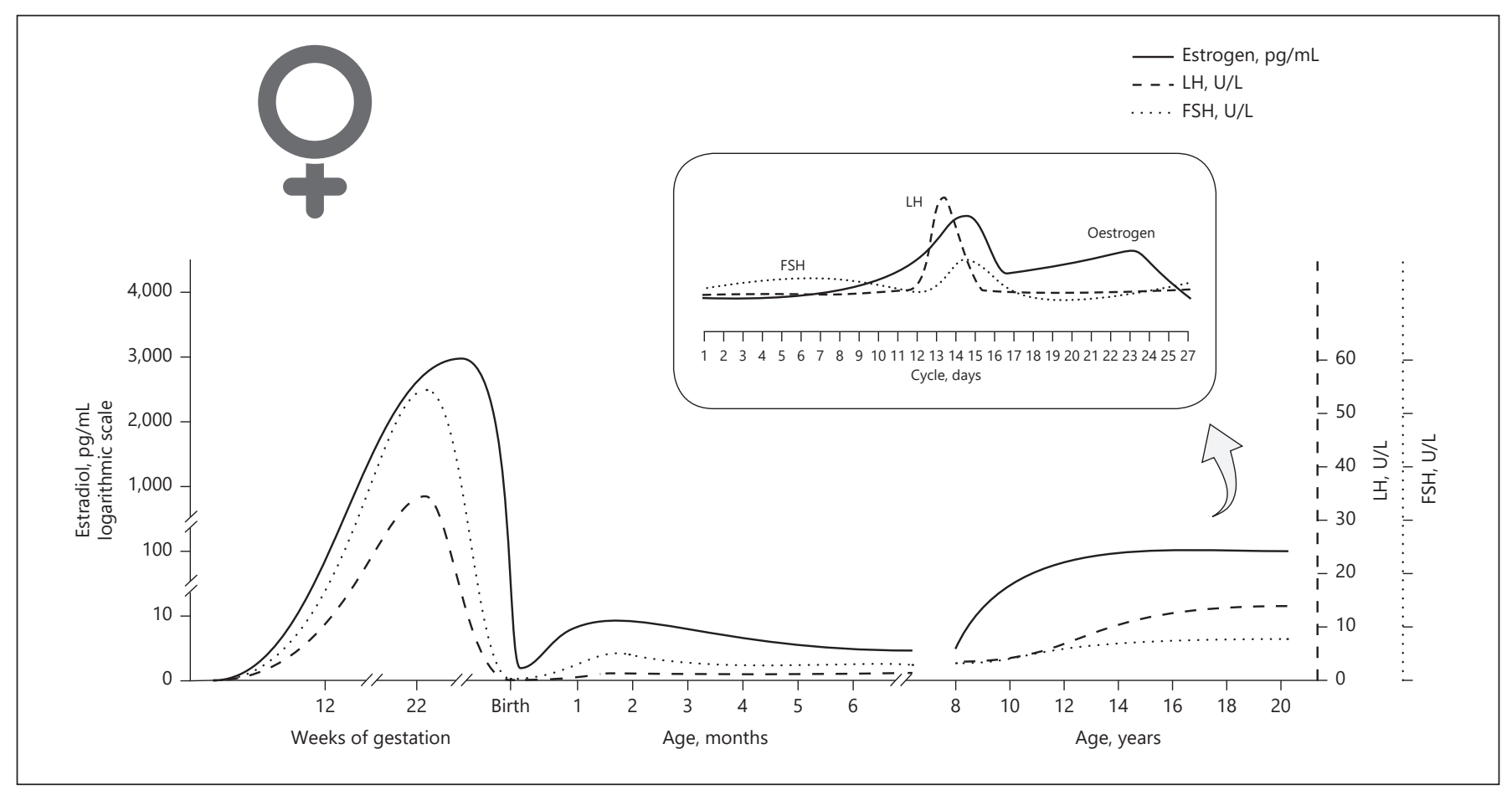

Fig. 2. Pattern of LH, FSH, and estradiol during the 3 endocrine puberties in girls.

In the male fetus, testosterone secretion (measured by RIA) peaks in the first trimester of pregnancy between the 11 th and 14th gestational week [6] (Fig. 1). Fetal testosterone is essential for normal genital development. The anogenital distance seems to be a marker of intrauterine androgen exposure [7]. Fetal testosterone also influences sexually dimorphic brain development [8].

In the female fetus, the rise of gonadotropins in utero is observed as well, but the estradiol production is predominantly of placental origin. The estradiol peak occurs in the third trimester of pregnancy (Fig. 2).

Corbier et al. [9] describe a sharp but short rise of testosterone (gas chromatography [GC]/MS) in male newborns, but no such rise was observed in girls.

\section{Minipuberty}

The second endocrine puberty takes places at the age of 1-6 months. This is the second transient activation of the HPG axis. Minipuberty was first described by Forest et al. [10] in 1973. Since then, the elevation of hormones at minipuberty has been well characterized, and an increasing number of studies have been published in an attempt to understand this phenomenon. Here, we review the current research on minipuberty, focusing on its influence upon: (1) the development of genital organs and fertility, (2) somatic development, (3) cognitive development, and (4) behavior.

\section{Hormonal Changes during Minipuberty}

The rise of gonadotropins ( $\mathrm{LH}$ and $\mathrm{FSH}$ ) observed in minipuberty stimulates testosterone production in the testicles in boys and estradiol production in the ovaries in girls (Fig. 1, 2).

After birth, in the absence of placental steroids suppressing the HPG axis, the HPG axis becomes progressively active again. Gonadotropin levels (RIA) rise approximately 1 week postnatally [11].

LH levels (RIA) are higher in boys than in girls, peaking between the 2 nd and 10 th week of life and declining thereafter to prepubertal levels by the age of 4-6 months [11-13]. FSH levels (RIA) are higher in girls than in boys during minipuberty [11-13] and stay elevated until the age of 3-4 years in girls, but not in boys (in whom a decline to prepubertal values occurs by the age of 6 months) [12].

In boys, LH stimulates testosterone production, so the level of testosterone increases (RIA), peaking in the 2nd-3rd month of life $[13,14]$. During this time, the 
testosterone values may reach those of fertile adult men $[13,14]$. Androgen production seems to occur rather via the backdoor pathway than the classic pathway [15]. Before the age of 6 months, testosterone levels will be again in the prepubertal range. There is a wide interindividual variation in testosterone values [13]. A study based on salivary testosterone measurements concluded that, in contrast to the strong genetic contribution observed in classical puberty, minipuberty seems to be strongly influenced by environmental factors. It has been found that genetic variants influencing salivary testosterone levels (detected by enzyme immunoassay [EIA]) in males are regulators of reproductive function and cholesterol; in females, genes related to estrogen signaling are more important [16]. Further studies are needed to understand the factors contributing to the interindividual variations in the transient sex hormone surge during minipuberty.

In some animal species, a transient activation of the HPG axis in males is observed. In monkeys, a postnatal rise of $\mathrm{LH}$ and testosterone (RIA) during the first 3 months is seen [17]. A testosterone surge (RIA) is also observed in neonatal male rats, male mice, and male foals [9].

Estradiol (RIA) rises more in girls than in boys [13, 14], with a level of Tanner stage 4 being normal in girls [18]. The difference between the sexes in the level of estradiol is, however, less significant than the level of testosterone $[13,14]$. A study based on urinary estradiol measurements (using LC-MS/MS) postulated fluctuations during minipuberty instead of a rise and subsequent fall of estradiol concentration; they observed huge intraindividual differences in serial urinary estradiol measurements [19].

Data on hormonal changes in minipuberty in preterm babies are scarce. Reference data based on serum measurements in 82 preterm babies for LH and FSH (measured by immunochemiluminometric assay [ICMA]) showed higher values for gonadotropins in preterm infants than in full-term infants, and higher LH and FSH values in preterm girls than in preterm boys [20]. This was confirmed by a study based on serial urinary measurements (using time-resolved immunofluorometric assay [TR-IFMA]) [21]. Data on testosterone and estradiol values during minipuberty are based only on serial urinary measurements (LC-MS/MS), showing a peak for testosterone 4 weeks after birth (higher in preterm than in full-term boys [22]) and fluctuating levels of estradiol (higher in preterm than in full-term girls [19]). Based on this evidence, it seems that the onset of minipuberty in preterm babies is similar to that in full-term babies, but that the HPG axis activation in the former is increased and prolonged, resulting in higher sex steroid concentrations than in the latter.

It is still not clear by which mechanism the activation of the HPG axis is silenced after a few months. Minipuberty is a window of opportunity to examine the HPG axis. A serum LH and FSH measurement in this period may help to diagnose infants with hypogonadotropic hypogonadism. Later in infancy, the HPG axis is physiologically quiescent, so diagnosing hypogonadotropic hypogonadism at this early stage can help to induce puberty at the appropriate physiological age. Since the hormonal rise is gender-specific during minipuberty, hormone analyses can help to classify biological sex in infants with a suspected disorder of sexual development (DSD). The observed optimal markers for the prediction of testicular tissue are anti-Müllerian hormone AMH (by EIA), T (by LC-MS/MS), and the LH/FSH ratio (by fluoroimmunoassay [FIA]) [23].

\section{Minipuberty and Its Influence on Genital Organ Development and Fertility}

In general, the transient rise in testosterone in boys or estradiol in girls is not followed by clinically visible physical changes. Ultrasound evaluation of testicular size may document a transient (not detectable by palpation) increase in testicular volume during minipuberty [24]. In rare cases, the transient rise of sex hormones can result in transient clinical visible pubertal signs in otherwise healthy infants: vaginal bleeding in girls [25] or palpable testicular growth with the development of pubic hair in boys [26, 27].

Regarding the persisting effects of minipuberty, the hormonal surge is of importance for penile growth and testicular development in boys. Testosterone levels (RIA) in minipuberty correlate positively with penile growth and penile growth velocity [28]. In preterm boys, the activation of the HGP axis is increased, with higher (urinary) LH (TR-IFMA) and testosterone (LC-MS/MS) concentrations than in full-term boys, resulting in a significantly faster testicular and penile growth [22]. In male babies suffering from hypogonadotropic hypogonadism, treatment with subcutaneously administered gonadotropins postnatally can provide normal penile growth and is an effective therapy for micropenis in infancy [29], but data about the outcome of long-term treatment are missing. Only 1 study has evaluated the long-term outcome of administering subcutaneous FSH in combination with intramuscular testosterone in the first months of life (in 
3 patients) [30]. This study showed no difference in inhibin $\beta$ values (as a marker for Sertoli cell function) at a pubertal age between infants that had been treated with gonadotropins at minipuberty and a nontreated control group. Penile length was not commented on in this study. More studies are warranted to evaluate the long-term efficacy of this treatment.

During minipuberty, an increase in the number of Sertoli cells [31] and germ cells [32] is observed in the testicles. As Sertoli cells do not express an androgen receptor during infancy, the rise in testosterone during minipuberty does not induce spermatogenesis [33]. However, the postnatal transient activation of the HPG axis seems to play an important role in fertility in boys. Several studies in cryptorchidic boys showed an insufficient maturation of gonadocytes into type A-dark spermatocytes [34]. Even after timely orchidopexy, there is a risk of infertility (38\% in bilateral cryptorchidism [35]), but an improved fertility index can be obtained after treatment with gonadotropin-releasing hormone $(\mathrm{GnRH})$ analog during the first year of life prior to orchidopexy [36]. This supports the hypothesis that cryptorchidism is not the cause of infertility, but rather a sign of a disturbed HPG axis. According to this hypothesis, the abnormal HPG axis and ensuing defective minipuberty influence future infertility. The current European guideline for urology from 2016 therefore suggests offering treatment with a $\mathrm{GnRH}$ analog to boys with bilateral undescended testes to improve their fertility outcome [37]. On the other hand, there are studies showing a higher rate of germ cell apoptosis in adults after prepubertal human chorionic gonadotropin (hCG) treatment for cryptorchidism [38]. As there is a lack of evidence of long-term efficacy to improve fertility by hormonal treatment, the current guideline of the American Urology Association from 2014 [37] and the consensus of the Nordic countries from 2007 [39] do not recommend hormone therapy. Further studies evaluating adult fertility and the potential side effects after preoperative GnRH therapy during the first year of life are therefore urgently required. In animal models, Li et al. [40] (using LC-MS/MS) and Chen et al. [41] (using enzyme-linked immunosorbent assay [ELISA]) showed that the postnatal transient testosterone surge influences gonocyte transformation and testicular function in male rats and mice.

In girls, there is less evidence to support the influence of minipuberty on fertility and development of the genital organs, but a positive correlation of the mammary gland diameter and estradiol (RIA) at the age of 3 months has been described [42]. Furthermore, in preterm girls, a positive correlation between urinary estradiol (LC-MS/MS) and uterine growth as well as mammary gland diameter has been observed [19]. There are no data available concerning longer-lasting effects of estradiol concentration during minipuberty on fertility or breast and uterine development in adult women.

\section{Minipuberty and Its Influence on Somatic \\ Development}

There are studies evaluating the influence of minipuberty on body composition and growth.

\section{Body Composition}

Hormone concentrations during minipuberty influence the somatic development during the first 6 years in boys. Testosterone (RIA) and LH (using microparticle enzyme immunoassay [MEIA]) concentrations during minipuberty correlate negatively with body weight and body mass index until the age of 6 years. The level of estradiol (RIA) during minipuberty correlates positively with the skin-fold thickness during the first 6 years.

No such influence has been observed in girls [13]. In studies on female rats, it has been demonstrated that postnatally administered estradiol and testosterone has a programming effect on the development of adipose tissue later in life $[43,44]$.

\section{Growth}

Data on the influence of minipuberty on growth velocity are conflicting. One study, with 84 participants, revealed a positive correlation of serial urinary testosterone (LC-MS/MS) on growth velocity in the first 6 months in boys and girls [45]. Another study, based on serial serum testosterone measurement in 35 babies, found no correlation between testosterone concentration (RIA) during minipuberty and growth velocity at any time point during the first 6 years [13]. Whether this difference is due to the different sampling materials (urinary vs. serum testosterone) or the small sample sizes needs to be elucidated by further studies.

In a retrospective study on infants with multiple pituitary hormone deficiency (including growth hormone deficiency), growth under early growth hormone substitution (starting in the first year of life) was improved in those not suffering from hypogonadism (but not in those with hypogonadism, and hence not having a minipuberty), suggesting a potential impact of minipuberty on growth during the first year of life [46].
Becker/Hesse 
Minipuberty and Its Influence on Cognitive

Development

The hormonal rise during minipuberty affects not only somatic development, but also cognitive development. Brain plasticity remains high during minipuberty and the brain continues to develop rapidly throughout the early postnatal period [47], making a possible influence of minipuberty on brain development conceivable.

It is a well-known fact that, on average, girls tend to acquire linguistic skills earlier and with a greater level of complexity than boys [48].

Several studies based on 1 cohort of patients showed associations of gonadotrophic and sex hormone values during minipuberty with speech development. In 4-weekold babies, recording event-related brain potentials (ERP) revealed a clear phonological discrimination effect with a bilateral distribution in girls. In boys, the discrimination effect was correlated with the testosterone value (RIA) at this age. Boys with a high level of testosterone showed no discrimination effect, but those with a low testosterone level showed a left lateralized discrimination effect [49].

The level of estradiol (RIA) at the age of 4 weeks has been positively correlated with the melody complexity in$\operatorname{dex}(\mathrm{MCI})$ at the age of 4 and 8 weeks. The MCI is an index of an infant's frequency modulation skills and provides melodic primitives for language [50]. The estradiol level (RIA) at the age of 4 weeks was also positively correlated to the individual infant's articulatory skills (by means of ART, which is a measure to evaluate the infant's ability to babble) at the age of 5 months. Interestingly, testosterone serum concentration (RIA) at the age of 20 weeks was negatively correlated with their babbling capacity [51]. The observation that "free estradiol" (SHBG$\mathrm{E}_{2}$ ) measured at the age of 5 months (RIA) was positively correlated and testosterone (RIA) was negatively correlated with sentence comprehension at the age of $4-5$ years could be interpreted as an expression of possible longterm effects [52].

These data are in line with the findings of a study based on salivary testosterone measurements (EIA). Salivary testosterone at the age of 1-3 months was negatively correlated to the size of the parent-reported expressive vocabulary in boys and in girls, and mediated the sex difference in the expressive vocabulary at 18-30 months of age [53].

These studies all suggest that sex hormone concentrations during minipuberty may indeed influence language development up to the age of 5 years. The findings are supported by animal studies which show that postnatally administered sex hormones influence brain development and behavior later in life $[54,55]$.

Minipuberty: Why Does it Happen?

\section{Minipuberty and Its Influence on Behavior}

There are several studies examining the influence of minipuberty on behavior. A study based on salivary testosterone measurement (EIA) in infants (males and females aged 3-4.9 months) revealed a correlation between testosterone levels and scores on the Distress to Limitations scale (based on the Infant Behavior Questionnairerevised, which was completed by their parents) in the male infants. Based on this study, it has been hypothesized that testosterone levels during minipuberty could influence emotional regulation in male infants [56]. A further study by this group showed that, in male infants, higher salivary androgen levels predicted a stronger preference for male-typical stimuli at the age of 3-4 months [57]. In this study cohort, no significant differences between the sexes in salivary testosterone levels (EIA), which are extremely sex-distinct during this time period in the serum (RIA) [13], were observed. This might have been due to the sampling material that was chosen or the delayed sampling time (after the age of 3 months). Based on the same cohort, a correlation of the obtained salivary testosterone values (EIA) at the age of 3-4.9 months with playbehavior and eye-contact time at the age of 19 months was analyzed. It was observed that there was no influence of salivary testosterone levels during minipuberty on gender-linked play behavior [58] or eye-contact time [59] in young children of either sex.

Another study, based on urinary testosterone measurement (LC-MS/MS) during the first 6 months of life, found a correlation to sex-typed behavior (evaluated by the Preschool Activity Inventory) at the age of 14 months [60]. This has been supported by a study which used penile growth during the first 3 months as an indirect marker for testosterone concentrations during minipuberty. This study revealed a significant positive correlation between penile growth during the first 3 months and masculine behavior, and a negative correlation with feminine behavior at the age of 3-4 years (assessed using the Preschool Activities Inventory) [61].

In studies with Rhesus monkeys, the manipulation of the postnatal testosterone surge significantly affected penile growth and development but did not affect the expression of sex differences in play and sexual behavior $[62,63]$.

A study which evaluated the influence of the first (in utero) endocrine puberty demonstrated a positive correlation of fetal testosterone (measured in the amniotic fluid by RIA) and the Quantitative Checklist for Autism in Toddlers (Q-CHAT) [64]. This raises the question of whether minipuberty (the second endocrine puberty)

Horm Res Paediatr 2020;93:76-84 DOI: $10.1159 / 000508329$ 
possibly influences autism spectrum disorder (ASD). Only a few studies have been conducted in this field. Salivary testosterone levels (EIA), measured in 84 infants at 3-4.9 months of life, revealed that higher postnatal testosterone concentrations in early infancy were predictive of higher scores on the ASD scale and lower verbalization at the age of 18 months [65]. Conflicting data were reported in another study, also based on salivary testosterone measurements (EIA) in 35 participants at the age of 3-4 months; the results suggested no relationship between testosterone and scores of the Q-CHAT in 18-24 months old children [66].

A more recent study has reevaluated whether salivary testosterone values (EIA) obtained at the age of 1-3 months (the sample timing corresponding better to the testosterone peak during minipuberty) correlated with the Q-CHAT score at the age of 18-30 months in 87 babies. In this study, no correlations of testosterone values and Q-CHAT scores were found in boys or girls [67]. Most likely, testosterone values during minipuberty are not associated with an increase in autistic traits, but further studies are needed to clarify this issue. The intrauterine effects of testosterone seem to be of more importance for autism development than the postnatal effects [64].

So far there is no clear evidence of an influence of sex hormone concentrations during minipuberty on sex-typical behavior. More studies are needed to address this question.

\section{Conclusion}

Minipuberty is the second physiological transient activation of the HPG axis occurring in healthy infants at the age of 1-6 months. It plays an important role in the development of the genital organs and fertility in males and seems to influence the development of their body composition. Furthermore, there is evidence suggesting a potential impact of minipuberty on language development in both sexes. Inconsistent data exist concerning the influence of minipuberty on behavior.

Many studies are based on salivary or urinary hormone analysis, for which a validation is still missing. LCMS/MS measurements are more reliable than direct immunoassays [2]. It is therefore important to take the sampling material and analytical method into account when evaluating studies concerning minipuberty.

Minipuberty is an interesting field of research and further studies will teach us more about this exciting period of human development.

\section{Acknowledgement}

We are grateful to Prof. Carine de Beaufort and Mr. Sean Sapcariu, $\mathrm{PhD}$, for critical review of the manuscript, and Mrs. Maële Dahin for her assistance with the graphs.

\section{Disclosure Statement}

The authors have no conflicts of interest to declare.

\section{Funding Sources}

The authors did not receive any funding.

\section{Author Contributions}

Both authors designed this review. M.B. drafted the manuscript and V.H. revised it critically. Both authors approved the final version to be published and agree to be accountable for all aspects of the work in ensuring that questions related to the accuracy or integrity of any part of the work are appropriately investigated and resolved.

\section{References}

1 Hesse V. The surge of sexual hormones in the first 6 months of life and its consequences: $\mathrm{mi}-$ nipuberty. Kinder- und Jugendarzt. 2019; 49(12):790-6. German

2 Hamer HM, Finken MJJ, van Herwaarden AE, du Toit T, Swart AC, Heijboer AC. Falsely elevated plasma testosterone concentrations in neonates: importance of LC-MS/MS measurements. Clin Chem Lab Med. 2018 24; 56(6):e141-3.
3 Grumbach M, Kaplan S. Fetal pituitary hormones and the maturation of the central nervous system regulation of anterior pituitary function. In: Glück L, editor. Modern Perinatal Medicine. Chicago (IL): Yearbook Medical Publishers; 1974. pp. 247-71.

4 Takagi S, Yoshida T, Tsubata K, Ozaki H, Fujii TK, Nomura Y, et al. Sex differences in fetal gonadotropins and androgens. J Steroid Biochem. 1977 May;8(5):609-20.
5 Troisi R, Potischman N, Roberts JM, Harger G, Markovic N, Cole B, et al. Correlation of serum hormone concentrations in maternal and umbilical cord samples. Cancer Epidemiol Biomarkers Prev. 2003 May;12(5):452-6.

6 Reyes FI, Boroditsky RS, Winter JS, Faiman C. Studies on human sexual development. II. Fetal and maternal serum gonadotropin and sex steroid concentrations. J Clin Endocrinol Metab. 1974 Apr;38(4):612-7. 
7 Thankamony A, Pasterski V, Ong KK, Acerini CL, Hughes IA. Anogenital distance as a marker of androgen exposure in humans. Andrology. 2016 Jul;4(4):616-25.

8 Lombardo MV, Ashwin E, Auyeung B, Chakrabarti B, Taylor K, Hackett G, et al. Fetal testosterone influences sexually dimorphic gray matter in the human brain. J Neurosci. 2012 Jan;32(2):674-80.

9 Corbier P, Edwards DA, Roffi J. The neonatal testosterone surge: a comparative study. Arch Int Physiol Biochim Biophys. 1992 Mar-Apr; 100(2):127-31.

10 Forest MG, Cathiard AM, Bertrand JA. Evidence of testicular activity in early infancy. J Clin Endocrinol Metab. 1973 Jul;37(1):14851.

11 Schmidt H, Schwarz HP. Serum concentrations of LH and FSH in the healthy newborn. Eur J Endocrinol. 2000 Aug;143(2):213-5.

12 Winter JS, Faiman C, Hobson WC, Prasad $\mathrm{AV}$, Reyes FI. Pituitary-gonadal relations in infancy. I. Patterns of serum gonadotropin concentrations from birth to four years of age in man and chimpanzee. J Clin Endocrinol Metab. 1975 Apr;40(4):545-51.

13 Becker M, Oehler K, Partsch CJ, Ulmen U, Schmutzler R, Cammann H, et al. Hormonal 'minipuberty' influences the somatic development of boys but not of girls up to the age of 6 years. Clin Endocrinol (Oxf). 2015 Nov; 83(5):694-701.

14 Winter JS, Hughes IA, Reyes FI, Faiman C. Pituitary-gonadal relations in infancy: 2. Patterns of serum gonadal steroid concentrations in man from birth to two years of age. J Clin Endocrinol Metab. 1976 Apr;42(4):679-86.

15 Dhayat NA, Dick B, Frey BM, d'Uscio CH, Vogt B, Flück CE. Androgen biosynthesis during minipuberty favors the backdoor pathway over the classic pathway: insights into enzyme activities and steroid fluxes in healthy infants during the first year of life from the urinary steroid metabolome. J Steroid Biochem Mol Biol. 2017;165(Pt B):31222.

16 Xia K, Yu Y, Ahn M, Zhu H, Zou F, Gilmore $\mathrm{JH}$, et al. Environmental and genetic contributors to salivary testosterone levels in infants. Front Endocrinol (Lausanne). 2014 Oct;5: 187.

17 Winter JS, Faiman C, Hobson WC, Prasad AV, Reyes FI. Pituitary-gonadal relations in infancy. I. Patterns of serum gonadotropin concentrations from birth to four years of age in man and chimpanzee. J Clin Endocrinol Metab. 1975 Apr;40(4):545-51.

18 Bidlingmaier F. [Sex differences in the secretion of gonadotropins and sex hormones in newborns and infants]. Fortschr Med. 1980 Feb;98(7):235-8.

19 Kuiri-Hänninen T, Haanpää M, Turpeinen U, Hämäläinen E, Seuri R, Tyrväinen E, et al. Postnatal ovarian activation has effects in estrogen target tissues in infant girls. J Clin Endocrinol Metab. 2013 Dec;98(12):4709-16.
20 Greaves RF, Hunt RW, Chiriano AS, Zacharin MR. Luteinizing hormone and folliclestimulating hormone levels in extreme prematurity: development of reference intervals. Pediatrics. 2008 Mar;121(3):e574-80.

21 Kuiri-Hänninen T, Dunkel L, Sankilampi U. Sexual dimorphism in postnatal gonadotrophin levels in infancy reflects diverse maturation of the ovarian and testicular hormone synthesis. Clin Endocrinol (Oxf). 2018 Jul; 89(1):85-92.

22 Kuiri-Hänninen T, Seuri R, Tyrväinen E, Turpeinen $U$, Hämäläinen E, Stenman $U H$, et al. Increased activity of the hypothalamic-pituitary-testicular axis in infancy results in increased androgen action in premature boys. J Clin Endocrinol Metab. 2011 Jan;96(1):98105.

23 Johannsen TH, Main KM, Ljubicic ML, Jensen TK, Andersen HR, Andersen MS, et al. Sex Differences in Reproductive Hormones During Mini-Puberty in Infants With Normal and Disordered Sex Development. J Clin Endocrinol Metab. 2018 Aug;103(8):3028-37.

24 Kuijper EA, van Kooten J, Verbeke JI, van Rooijen M, Lambalk CB. Ultrasonographically measured testicular volumes in 0 - to 6-year-old boys. Hum Reprod. 2008 Apr; 23(4):792-6.

25 de Lange AH, Bocca G. Vaginal bleeding in a 4-month-old preterm girl: extreme minipuberty mimicking central precocious puberty. J Pediatr Endocrinol Metab. 2013;26(5-6): 595-7.

26 Becker M, Hesse V. Premature pubarche in an infant. Monatsschr Kinderheilkd. 2018 Jul; 166(7):556-9. German

27 Bourayou R, Giabicani E, Pouillot M, BraillyTabard S, Brauner R. Premature pubarche before one year of age: distinguishing between mini-puberty variants and precocious puberty. Med Sci Monit. 2015 Apr;21:955-63.

28 Boas M, Boisen KA, Virtanen HE, Kaleva M, Suomi AM, Schmidt IM, et al. Postnatal penile length and growth rate correlate to serum testosterone levels: a longitudinal study of 1962 normal boys. Eur J Endocrinol. 2006 Jan; 154(1):125-9.

29 Main KM, Schmidt IM, Toppari J, Skakkebaek NE. Early postnatal treatment of hypogonadotropic hypogonadism with recombinant human FSH and LH. Eur J Endocrinol. 2002 Jan;146(1):75-9.

30 Kohva E, Huopio H, Hietamäki J, Hero M, Miettinen PJ, Raivio T. Treatment of gonadotropin deficiency during the first year of life: long-term observation and outcome in five boys. Hum Reprod. 2019 May;34(5):863-71.

31 Cortes D, Müller J, Skakkebaek NE. Proliferation of Sertoli cells during development of the human testis assessed by stereological methods. Int J Androl. 1987 Aug;10(4):589-96.

32 Müller J, Skakkebaek NE. Fluctuations in the number of germ cells during the late foetal and early postnatal periods in boys. Acta Endocrinol (Copenh). 1984 Feb;105(2):271-4.
33 Chemes HE, Rey RA, Nistal M, Regadera J, Musse M, González-Peramato P, et al. Physiological androgen insensitivity of the fetal, neonatal, and early infantile testis is explained by the ontogeny of the androgen receptor expression in Sertoli cells. J Clin Endocrinol Metab. 2008 Nov;93(11):4408-12.

34 Hadziselimovic F, Herzog B. The importance of both an early orchidopexy and germ cell maturation for fertility. Lancet. 2001 Oct; 358(9288):1156-7.

35 Lee PA, O'Leary LA, Songer NJ, Coughlin MT, Bellinger MF, LaPorte RE. Paternity after bilateral cryptorchidism. A controlled study. Arch Pediatr Adolesc Med. 1997 Mar;151(3): 260-3.

36 Schwentner C, Oswald J, Kreczy A, Lunacek A, Bartsch G, Deibl M, et al. Neoadjuvant gonadotropin-releasing hormone therapy before surgery may improve the fertility index in undescended testes: a prospective randomized trial. J Urol. 2005 Mar;173(3):974-7.

37 Kolon TF, Herndon CD, Baker LA, Baskin LS, Baxter CG, Cheng EY, et al.; American Urological Assocation. Evaluation and treatment of cryptorchidism: AUA guideline. J Urol. 2014 Aug;192(2):337-45.

38 Dunkel L, Taskinen S, Hovatta O, Tilly JL, Wikström S. Germ cell apoptosis after treatment of cryptorchidism with human chorionic gonadotropin is associated with impaired reproductive function in the adult. J Clin Invest. 1997 Nov;100(9):2341-6.

39 Ritzén EM, Bergh A, Bjerknes R, Christiansen $\mathrm{P}$, Cortes D, Haugen SE, et al. Nordic consensus on treatment of undescended testes. Acta Paediatr. 2007 May;96(5):638-43.

40 Li R, Vannitamby A, Yue SS, Handelsman D, Hutson J. Mouse minipuberty coincides with gonocyte transformation into spermatogonial stem cells: a model for human minipuberty. Reprod Fertil Dev. 2017 Nov;29(12):2430-6.

41 Chen L, Wang R, Wang W, Lu W, Xiao Y, Wang D, et al. Hormone Inhibition During Mini-Puberty and Testicular Function in Male Rats. Int J Endocrinol Metab. 2015 Oct 13(4):e25465.

42 Schmidt IM, Chellakooty M, Haavisto AM, Boisen KA, Damgaard IN, Steendahl U, et al. Gender difference in breast tissue size in infancy: correlation with serum estradiol. Pediatr Res. 2002 Nov;52(5):682-6.

43 Nilsson C, Niklasson M, Eriksson E, Björntorp P, Holmäng A. Imprinting of female offspring with testosterone results in insulin resistance and changes in body fat distribution at adult age in rats. J Clin Invest. 1998 Jan; 101(1):74-8.

44 Alexanderson C, Stener-Victorin E, Kullberg J, Nilsson S, Levin M, Cajander S, et al. A single early postnatal estradiol injection affects morphology and gene expression of the ovary and parametrial adipose tissue in adult female rats. J Steroid Biochem Mol Biol. 2010 Oct; 122(1-3):82-90. 
45 Kiviranta P, Kuiri-Hänninen T, Saari A, Lamidi ML, Dunkel L, Sankilampi U. Transient Postnatal Gonadal Activation and Growth Velocity in Infancy. Pediatrics. 2016 Jul;138(1):e20153561.

46 Cetinkaya S, Poyrazoğlu S, Baș F, Ercan O, Yildız M, Adal E, et al. Response to growth hormone treatment in very young patients with growth hormone deficiencies and minipuberty. J Pediatr Endocrinol Metab. 2018 Jan;31(2):175-84.

47 de Graaf-Peters VB, Hadders-Algra M. Ontogeny of the human central nervous system: what is happening when? Early Hum Dev. 2006 Apr;82(4):257-66.

48 Berglund E, Eriksson M, Westerlund M. Communicative skills in relation to gender, birth order, childcare and socioeconomic status in 18-month-old children. Scand J Psychol. 2005 Dec;46(6):485-91.

49 Friederici AD, Pannekamp A, Partsch CJ, Ulmen U, Oehler K, Schmutzler R, et al. Sex hormone testosterone affects language organization in the infant brain. Neuroreport. 2008 Feb;19(3):283-6.

50 Wermke K, Hain J, Oehler K, Wermke P, Hesse V. Sex hormone influence on human infants' sound characteristics: melody in spontaneous crying. Biol Lett. 2014 May; 10(5):20140095.

51 Quast A, Hesse V, Hain J, Wermke P, Wermke $\mathrm{K}$. Baby babbling at five months linked to sex hormone levels in early infancy. Infant Behav Dev. 2016 Aug;44:1-10.
52 Schaadt G, Hesse V, Friederici AD. Sex hormones in early infancy seem to predict aspects of later language development. Brain Lang. 2015 Feb;141:70-6.

53 Kung KT, Browne WV, Constantinescu M, Noorderhaven RM, Hines M. Early postnatal testosterone predicts sex-related differences in early expressive vocabulary. Psychoneuroendocrinology. 2016 Jun;68:111-6.

54 Adkins-Regan E, Mansukhani V, Seiwert C, Thompson R. Sexual differentiation of brain and behavior in the zebra finch: critical periods for effects of early estrogen treatment. J Neurobiol. 1994 Jul;25(7):865-77.

55 Fitch RH, Denenberg VH. A role for ovarian hormones in sexual differentiation of the brain. Behav Brain Sci. 1998 Jun;21(3):31127.

56 Alexander GM, Saenz J. Postnatal testosterone levels and temperament in early infancy. Arch Sex Behav. 2011 Dec;40(6):1287-92.

57 Alexander GM, Wilcox T, Farmer ME. Hormone-behavior associations in early infancy. Horm Behav. 2009 Nov;56(5):498-502.

58 Alexander GM, Saenz J. Early androgens, activity levels and toy choices of children in the second year of life. Horm Behav. 2012 Sep; 62(4):500-4.

59 Saenz J, Alexander GM. Digit ratios (2D:4D), postnatal testosterone and eye contact in toddlers. Biol Psychol. 2013 Sep;94(1):106-8.

60 Lamminmäki A, Hines M, Kuiri-Hänninen T, Kilpeläinen L, Dunkel L, Sankilampi U. Testosterone measured in infancy predicts subsequent sex-typed behavior in boys and in girls. Horm Behav. 2012 Apr;61(4):611-6.
61 Pasterski V, Acerini CL, Dunger DB, Ong KK, Hughes IA, Thankamony A, et al. Postnatal penile growth concurrent with mini-puberty predicts later sex-typed play behavior: evidence for neurobehavioral effects of the postnatal androgen surge in typically developing boys. Horm Behav. 2015 Mar;69:98-105.

62 Wallen K, Maestripieri D, Mann DR. Effects of neonatal testicular suppression with a $\mathrm{GnRH}$ antagonist on social behavior in group-living juvenile rhesus monkeys. Horm Behav. 1995 Sep;29(3):322-37.

63 Nevison CM, Brown GR, Dixson AF. Effects of altering testosterone in early infancy on social behaviour in captive yearling rhesus monkeys. Physiol Behav. 1997 Dec;62(6):1397403.

64 Auyeung B, Taylor K, Hackett G, Baron-Cohen S. Foetal testosterone and autistic traits in 18 to 24-month-old children. Mol Autism. 2010 Jul;1(1):11.

65 Saenz J, Alexander GM. Postnatal testosterone levels and disorder relevant behavior in the second year of life. Biol Psychol. 2013 Sep; 94(1):152-9.

66 Auyeung B, Ahluwalia J, Thomson L, Taylor K, Hackett G, O’Donnell KJ, et al. Prenatal versus postnatal sex steroid hormone effects on autistic traits in children at 18 to 24 months of age. Mol Autism. 2012 Dec;3(1):17.

67 Kung KT, Constantinescu M, Browne WV, Noorderhaven RM, Hines M. No relationship between early postnatal testosterone concentrations and autistic traits in 18 to 30 -monthold children. Mol Autism. 2016 Feb;7(1):15. 